\title{
Orthodontic retention procedures: Retrospective statistical study
}

\author{
Mijloace de contenție ortodontică: Studiu statistic retrospectiv
}

\author{
Mioara Decusară, Gina-Păunița Grecu, Daniela Cornea, Dorina-Cerasella Șincar \\ Departamentul de Medicină Dentară, Facultatea de Medicină și Farmacie, \\ Universitatea "Dunărea de Jos", Galați, România
}

\begin{abstract}
Objectives. This retrospective study aimed to analyse the orthodontic retention procedures used for the stability of orthodontic treatment results and the prevention of relapse.

Material and method. The study was performed over a period of 24 months, analyzing the type of procedures used for orthodontic contention for 124 patients, at age between 14 and 49 years, treated orthodontically with fixed bimaxillary apparatus, the wearing time of these devices being between 24 and 30 months. To these patiens were applied Hawley plate, vacuum-formed retainer and fixed collate retainer, depending on the dento-maxillary abnormalities, orthodontic treatment with or without extractions, dento-periodontal status and existing clinical situation, as well as the collaboration with the patients.

Conclusions. To be effective, the restraint must be immediate, correctly applied or used for a long period of time.
\end{abstract}

Keywords: orthodontic treatment, relapse, ortodontic retention procedures

\section{REZUMAT}

Obiective. Acest studiu a urmărit analiza retrospectivă a mijloacelor de contenție utilizate pentru stabilitatea rezultatelor tratamentului ortodontic și prevenirea recidivei.

Material şi metodă. Studiul a fost efectuat pe o perioadă de 24 de luni, analizând tipul de aparat folosit pentru contenție pentru 124 de pacienți, cu vârste cuprinse între 14 și 49 de ani, tratați ortodontic cu aparate fixe bimaxilar, timpul de purtare a aparatelor fixe fiind între 24 şi 30 luni. Acestor pacienți li s-au aplicat aparate de contenție de tip placă Hawley, gutiere termoformabile și retainere colate, în funcție de anomalia dento-alveolară tratată, cu sau fără extracții, statusul dento-parodontal și șituația clinică existentă, precum și de colaborarea acestora.

Concluzii. Pentru a fi eficientă, contenția trebuie să fie imediată, corect aplicată sau utilizată și pentru o perioadă lungă de timp.

Cuvinte cheie: tratament ortodontic, recidivă, mijloace de contenție

\section{INTRODUCERE}

Mijloacele de contenție sunt utilizate după un tratament ortodontic pentru a menține rezultatele obținute si a preveni astfel recidiva. În literatura de specialitate, nu sunt multe cercetări științifice privind necesitatea contenției și metodele utilizate, cele mai multe dintre lucrările publicate având la bază experiența practică a medicului ortodont (1).
Contenţia este perioada care urmează tratamentului ortodontic activ prin care dinţii trebuie menţinuţi pentru o perioadă cât mai lungă de timp în noua lor poziție. În cele mai multe cazuri, dacă această fază a tratamentul nu are loc, atunci există foarte mari șanse de recidivă, din cauza faptului că atât osul, cât și țesutul parodontal și țesuturile moi necesită timp pentru a se adapta şi a se reface după mișcarea ortodontică $(1,2)$. Din momentul în care 
dinții sunt deplasați, apare resorbția osoasă (înaintea rădăcinii) și apoziție osoasă (formare de os nou în spatele rădăcinii), ciclul de remodelare osoasă fiind de aproximativ 6 luni. Prin urmare, pentru a evita recidiva, contenția trebuie să fie pentru o perioadă de cel puțin 6 luni după alinierea tuturor dinților. Și țesuturile moi (gingie, ligament parodontal, buze, obraji și limbă) au, de asemenea, un important rol în stabilitate și apariţia recidivei. Ligamentul parodontal şi în special fibrele gingivale (elastice) supracrestale se adaptează după cel puțin 9 luni la noua poziție a dinților deplasați ortodontic şi nu este sigur că aceste fibre se vor adapta vreodată pe deplin. Aceasta înseamnă că există situații clinice în care stabilitatea dentară nu va fi realizabilă și recidiva este oricând posibilă, mijloacele de contenție fiind cele care ajută la menținerea rezultatelor $(2,3)$.

De aceea, este importantă explicarea necesității aplicării mijloacelor de contenție și purtarea adecvată a acestuia, constituindu-se ca fază pasivă a tratamentului ortodontic, pentru a minimaliza recidiva si a evita dezamăgirea pacienţilor şi a părinţilor $(4,5)$.

Pentru practicianul ortodont, este important să cunoască și să aplice câteva principii de mecanică ortodontică pentru a reduce riscul de recidivă $(5,6)$ :

Supracorecția overjet-ului și overbite-ului în timpul tratamentului ortodontic al cazurilor de ocluzie deschisă, ocluzie adâncă acoperită, anomalii dento-alveolare de clasa a III-a și clasa II/1 Angle

Supracorecția rotaţiilor, mai ales a celor de la nivelul incisivilor inferiori, în fazele de început ale tratamentului ortodontic; pentru rotațiile severe unii specialişti recomandă fibrotomii supracrestale, precum şi reconturarea coroanelor triunghiulare $\mathrm{cu}$ eliminarea contactelor interproximale de tip punctiform

Frenectomia unui fren al buzei superioare, gros și cu inserție joasă, care a determinat diastemă

Evitarea lărgirii arcadei inferioare și a creșterii distanței intercanine pentru a rezolva înghesuirile dentare, deoarece apar de cele mai multe ori recidive și probleme parodontale.

\section{Tipuri de aparate de contenţie}

În prezent, dispozitivele de contenţie (aşanumitele retainere) se împart în dispozitive detaşabile sau fixe. Se pot aplica la arcada superioară sau inferioară (sau la ambele, așa cum se întâmplă în cea mai mare parte), fiind realizate pe modele din gips turnate în amprentele arcadelor dentare după îndepărtarea aparatelor fixe.

Aparatele de contenție mobilizabile sunt: placa Hawley (și variațiile acesteia), aparatele de contenție conformate prin vacuum (VFR, placa Essix sau gutierele termoformabile) și positionerele $(5,6)$.

Placa Hawley clasică este formată din baza plăcii palatinale sau linguale (acrilică), la care se pot încorpora un şurub ortodontic, un arc vestibular cu buclă în „U““ (poziționat între canin și premolar) și croșete Adams (pe molar), fabricarea acestora fiind destul de costisitoare. Are avantajul că nu acoperă suprafața ocluzală a dinților, poate fi purtat și în timpul mesei, poate fi activat la nivelul arcului vestibular sau al croșetelor, dar nu menține întotdeauna dinții în sens vertical sau sagital, ceea ce poate duce la malocluzii sau rotații dentare (recidivă) $(1,6)$.

Ca variante modificate ale plăcii Hawley, există $(5,7)$ :

- acoperirea cu masă acrilică transparentă a arcului vestibular, la nivelul incisivilor (mezial de canini), transformând astfel arcul într-o atelă acrilică care menține incisivii „strânși““ între aceasta și baza plăcii palatinale.

- utilizarea unui arc vestibular extins distal de ultimul molar (fără croșete), ceea ce stabilizează ocluzia și menține dimensiunea transversală posterioară a arcadei superioare.

Gutierele termoformabile (placa Essix) necesită pentru fabricare un echipament de termoformare cu vacuum și plăci din poliester sau polivinil, de dimensiuni de la 0,5-3 $\mathrm{mm}$, dure sau elastice, transparente sau opace. Ele sunt preferate de pacienți datorită esteticii, costurilor de fabricație, menţinerii stabilității dinților și ușurinței de purtare și întreținere. Prezintă însă și dezavantaje: acoperă suprafața ocluzală a dinților, cu menținerea redusă a mișcărilor verticale și a spațiilor închise după extracții dentare sau diastemă și deteriorarea rapidă dacă sunt purtate în timpul mesei sau la pacienții cu bruxism $(7,8)$.

Positionerele sunt utilizate după îndepărtarea aparatelor fixe pentru menţinerea poziției dinţilor în cazul îndepărtării premature, după corectarea 
ocluziei deschise frontale (cu efect de închidere verticală a ocluziei) sau a poziției mandibulei (în sens sagital). Sunt însă mai greu acceptate și purtate de pacienți, iar tehnica de confecționare este mult mai laborioasă și costisitoare (5).

Dispozitivele de contenție fixe (retainerele colate) sunt realizate din fir de oțel inoxidabil împletit sub forma unui arc subțire, cu diametrul firelor individuale și a grosimii totale a firelor variabil (în medie, între 0,0175 şi 0,022 inci). Se pot utiliza şi fire rotunde (blue Elgiloy), rectangulare (din titan), retainere prefabricate sau fabricate în laborator din arcuri de NiTi. Aceste arcuri oferă o cantitate mică de flexibilitate (permițând mișcarea fiziologică) între fiecare dinte, ceea ce face ca desprinderea să fie mai puțin probabilă (spre deosebire de retainerele colate din sârmă groasă sau rigidă) (9). Retainerul se colează de la canin la canin, pe fața linguală, după adaptarea acestuia pe modelul din gips, curățarea dinților, pregătirea smalțului și utilizarea unui material de colaj adecvat. Dacă sunt bine adaptate și fixate printr-o tehnică precisă, retainerele colate pot rezista fără să se desprindă mulți ani, un rol important avându-1 și pacientul, prin respectarea indicațiilor privind îngrijirea retainerului, alimentația și controalele periodice $(9,10)$.

$\mathrm{Au}$ fost efectuate diverse studii privind contenţia utilizată de specialiștii ortodonți pentru evaluarea tipurilor de contenție utilizate și pentru care situații clinice sunt indicate, protocolul privind aplicarea acestora, recomandările date pacienților și protocolul privind controalele periodice (11-14).

\section{SCOP}

Scopul acestui studiu a fost acela de a face o analiză retrospectivă a mijloacelor de contenție utilizate pentru prevenirea recidivei și menținerea stabilității dentare după tratamentul ortodontic cu aparate fixe.

\section{MATERIAL ŞI METODĂ}

Studiul a fost efectuat pe o perioadă de 24 de luni după analiza fișelor de tratament ortodontic pe un lot de 124 de pacienți, cu vârste cuprinse între 14 și 49 de ani, tratați ortodontic cu aparate fixe bimaxilar, timpul de purtare a aparatelor fixe fiind între 24 şi 30 luni. Acestor pacienți li s-au aplicat aparate de contenție de tip placă Hawley, gutiere termoformabile și retainere colate, în funcție de anomalia dento-alveolară tratată, cu sau fără extracții, de statusul dento-parodontal și situația clinică existentă și, nu în ultimul rând, de colaborarea pacienţilor.

Aparatele de contenție tip placă Hawley (unele cu șurub ortodontic montat median) au fost recomandate pentru menținerea rezultatelor în ocluzia deschisă, ocluzia adâncă acoperită, în anomaliile de clasa a II-a și clasa a III-a Angle, în compresiile de maxilar (după expansiune transversală RPE) și la pacienții adolescenți (în creștere pubertară sau cu igienă dentară defectuoasă).

Gutierele termoformabile au fost utilizate mai mult la arcada superioară, la pacienții la care au fost efectuate extracții în scop ortodontic (înghesiri dentare), la cei cu probleme parodontale, la care s-a desprins sau au solicitat îndepărtarea contenției colate și la pacienții cu bruxism nocturn.

Retainere colate au fost aplicate de regulă la arcada mandibulară, de la canin la canin, în combinație cu placa Hawley sau contențiile conformate prin vacuum. Retențiile fixe superioare colate lingual au fost aplicate pentru menținerea alinierii dinților frontali la adulți, când suportul parodontal era redus, și la pacienții tratați pentru treme și diasteme (microdenție sau anodonție de incisivi laterali).

La pacienții adulți tratați ortodontic pentru alinierea dinţilor malpoziţionați, din cauza bolii parodontale și atrofiilor osoase orizontale generalizate, au fost aplicate retainere colate lingual bimaxilar și gutiere termoformabile.

\section{REZULTATE}

Studiul a fost efectuat pe un număr de 124 pacienți, dintre care 95 femei (77\%) și 114 (92\%) din mediul urban (fig. 1).

Analizând vârsta pacienților, 51\% (63 pacienți) aveau vârsta între 14 şi 20 ani, 27\% (34 pacienţi) aveau între 20 şi 30 ani, 18\% (22 pacienți) erau între 30 şi 40 ani și $4 \%$ (5 pacienți) erau de peste 50 ani (fig. 2).

Cazuistica pentru care au fost tratați ortodontic este reprezentată în figura 3.

Din totalul de 124 pacienți, tratamentul ortodontic a fost fără extracții dentare la $63 \%$ (78 cazuri), 29\% (36 pacienți) au suferit extracții în scop 

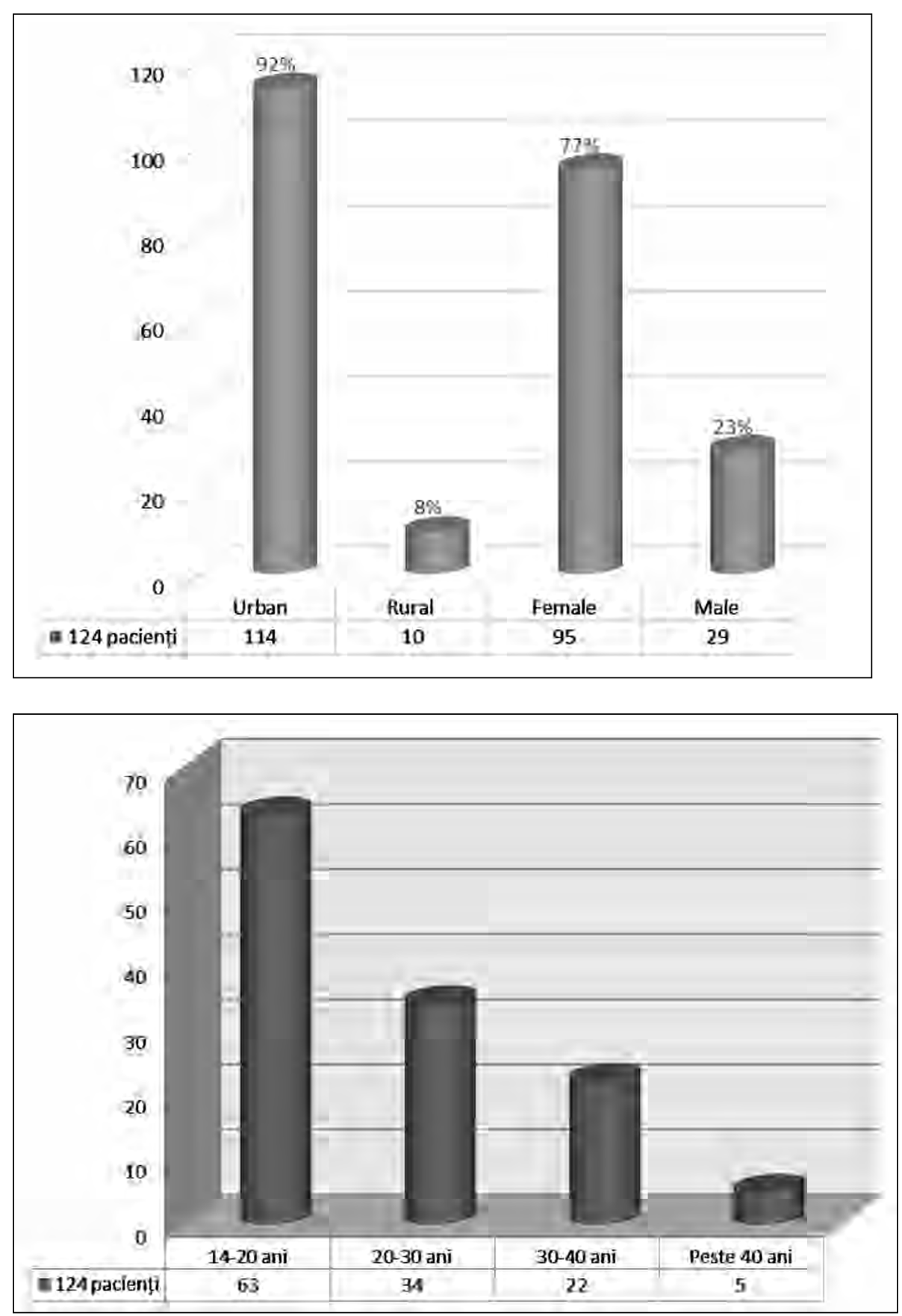

FIGURA 1. Repartiţia pacienţilor în funcţie de sex şi mediul de provenienţă ortodontic, iar 8\% (19 pacienți) au beneficiat de tratament ortodontic cu aparat fix în scop preprotetic și de reabilitare orală complexă (fig. 4).

În figura 5 este reprezentată distribuția pacienților în funcție de tipul de contenție aplicat la finalul tratamentului ortodontic fix.

Dacă ar fi realizată o sinteză personală a celor prezentate anterior, se poate spune că nu există un mijloc de contenție "ideal", aplicabil tuturor pacienților care au beneficiat de tratament ortodontic cu aparat fix, alegerea acestuia având la bază experiența practică a ortodontului, anomalia dento- alveolară tratată, situațiile clinice existente și, nu în ultimul rând, cooperarea pacientului (tabel 1).

\section{DISCUŢII}

Deplasarea dentară, cu sau fără modificări ocluzale, apare frecvent după un tratament ortodontic activ, cu sau fără extracții, dar și în cazul unor pacienţi netrataţi ortodontic, fiind un fenomen normal, corespunzător înaintării în vârstă, care continuă toată viața $(4,5,15)$.

Este bine ca pacienţilor să li se explice aceste lucruri, precum și faptul că, după tratamentul 


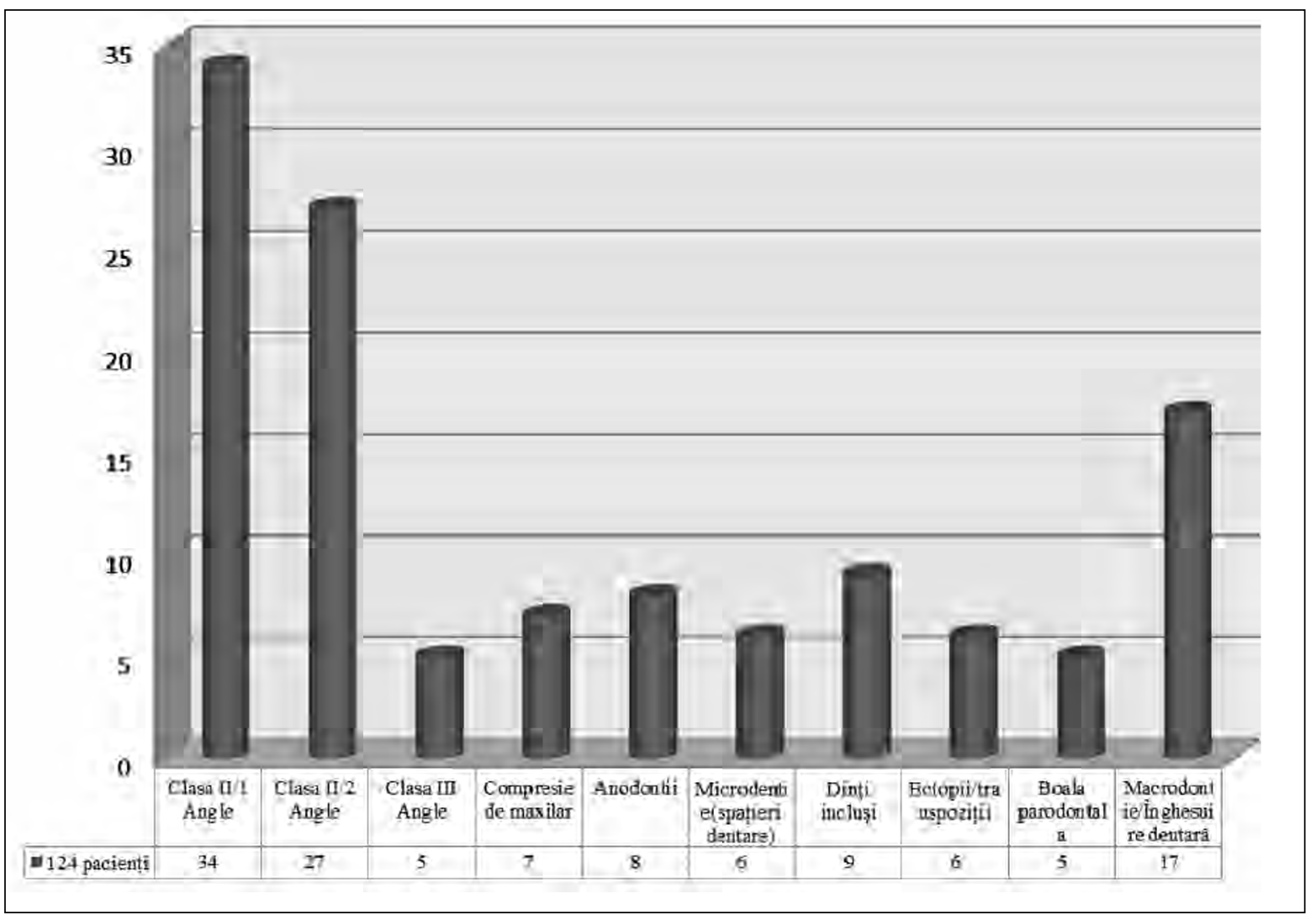

FIGURA 3. Repartiţia pacienţilor în funcţie de anomaliile dento-maxilare şi statusul dento-parodontal

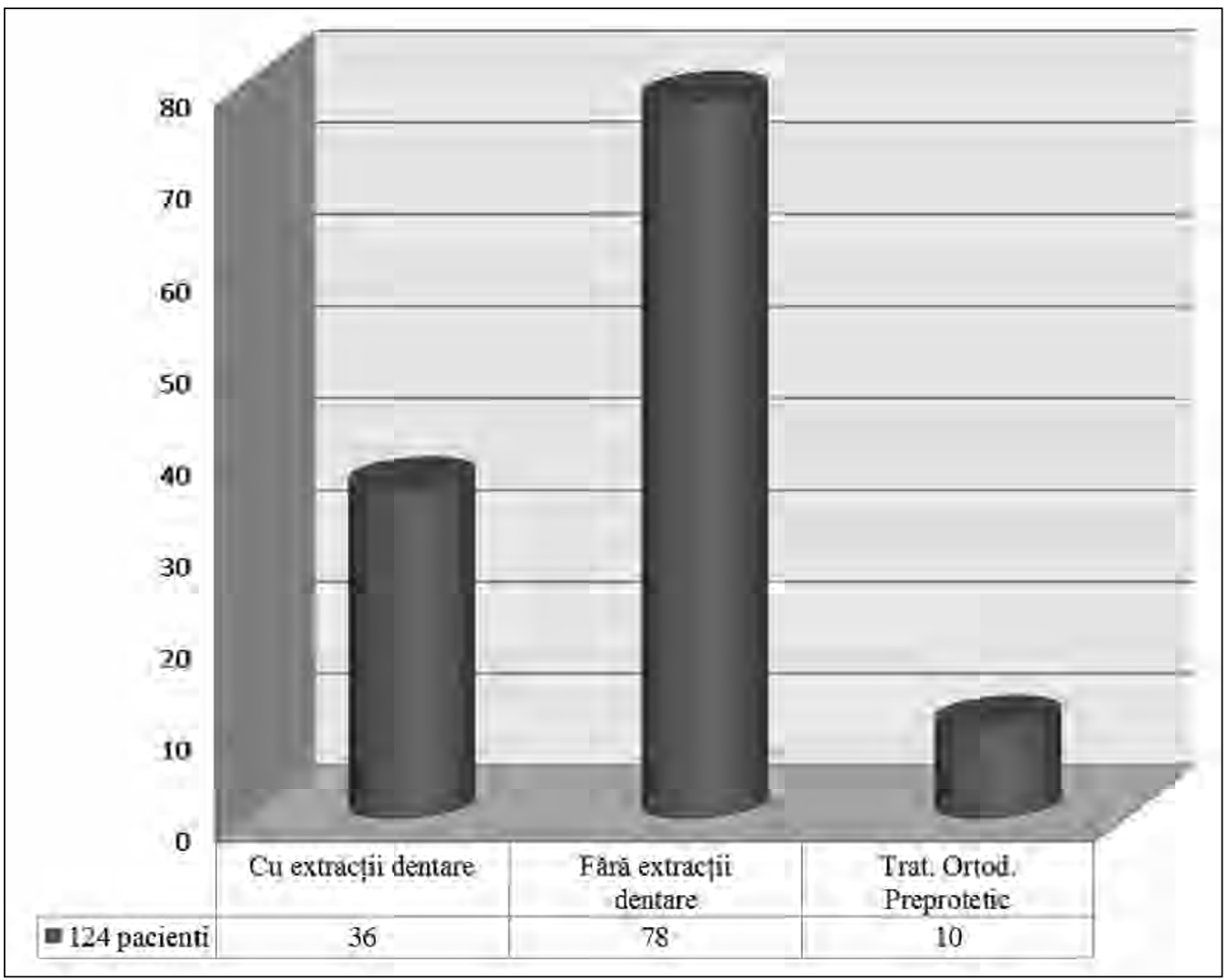




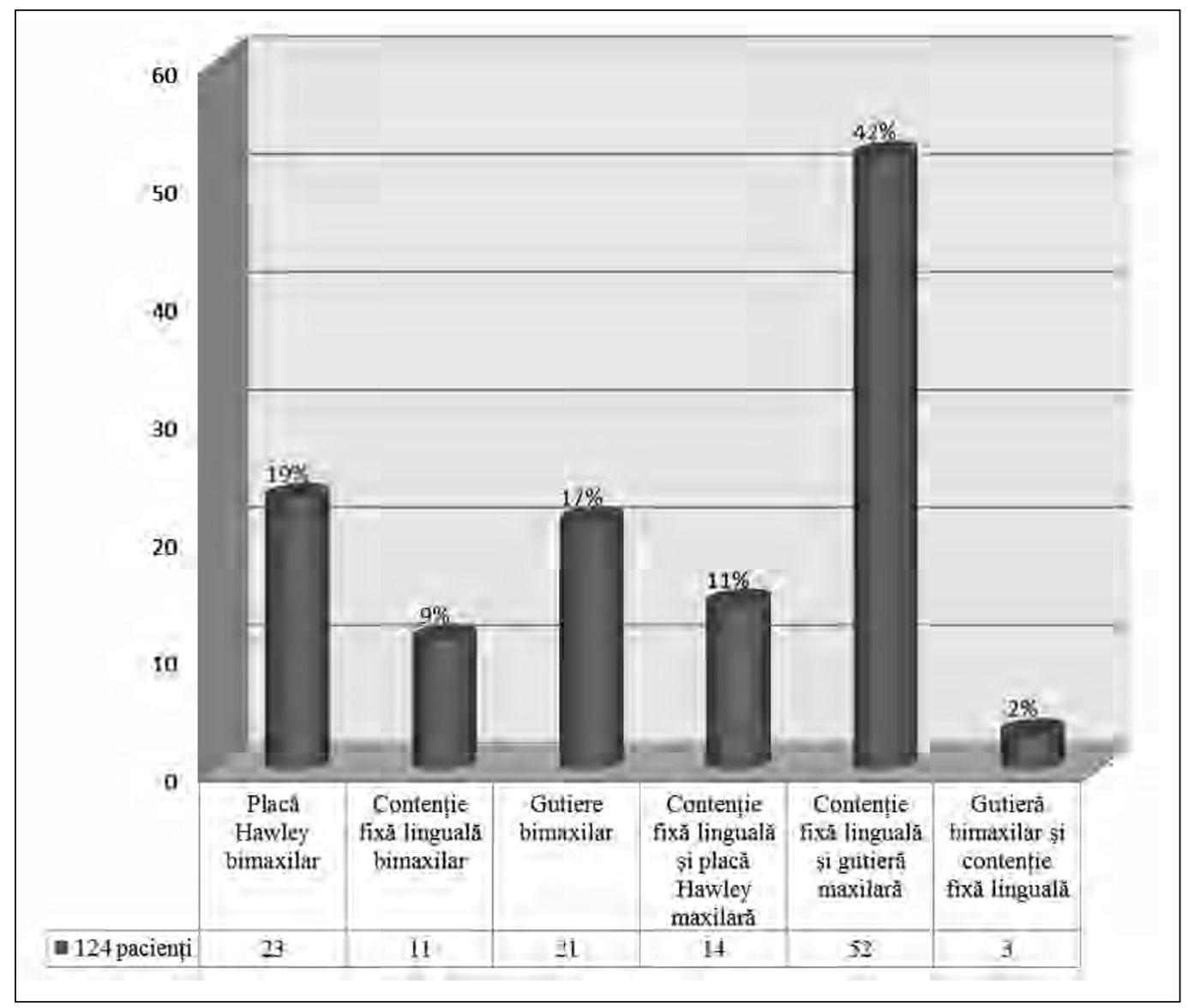

FIGURA 5. Distribuţia pacienţilor în funcţie de tipul de contenţie aplicat

TABEL 1. Prezentare personală a tipurilor de contenţie în funcţie de avantaje şi dezavantaje

\begin{tabular}{|l|c|c|c|c|c|c|c|}
\hline $\begin{array}{l}\text { Tipul de } \\
\text { contenție }\end{array}$ & $\begin{array}{c}\text { Menținerea } \\
\text { alinierii } \\
\text { dentare }\end{array}$ & $\begin{array}{c}\text { Menținerea } \\
\text { corecției } \\
\text { overjet-ului }\end{array}$ & $\begin{array}{c}\text { Menținerea } \\
\text { sănătăți dento- } \\
\text { parodont. }\end{array}$ & $\begin{array}{c}\text { Menținerea } \\
\text { spațiilor } \\
\text { închise }\end{array}$ & $\begin{array}{c}\text { Rezistența la } \\
\text { rupere }\end{array}$ & Estetica & $\begin{array}{c}\text { Ușor de purtat } \\
\text { și reparat }\end{array}$ \\
\hline Placa Hawley & ++ & ++ & ++ & + & + & - & - \\
\hline Placa Essix & +++ & +++ & ++ & +++ & + & ++ & + \\
\hline Retainer colat & +++ & +++ & +++ & +++ & + & +++ & ++ \\
\hline
\end{tabular}

ortodontic, cei mai predispuși la recidivă și la modificările posttratament sunt incisivii, dinţii care îi interesează cel mai mult pe pacienți în ceea ce privește alinierea și zâmbetul. Factorii care pot determina recidiva, necesitând astfel contenție obligatorie, sunt: parodontali, alveolari, țesuturile moi (limba, obraji), ocluzali și de creștere, unele obiceiuri vicioase $(14,15,16)$.

Este important ca pacienţii să cunoască faptul că tratamentul ortodontic cuprinde o fază activă, reprezentată de deplasarea dinților și obținută cu ajutorul aparatelor ortodontice, și o fază finală pasivă, pentru stabilizarea poziției dinților și prevenirea recidivei, realizată prin intermediul aparatelor de contenție $(16,17)$.

Scopul contenției nu este de a elimina toate cauzele de recidivă şi de a asigura stabilitatea trata- mentului, ci de a elimina o principală cauză de recidivă, și anume reacțiile parodontale consecutive deplasării ortodontice a dinților. Celelalte cauze ale recidivei ar trebui eliminate prin tratamentul ortodontic și nu prin contenție. Numai contenția permanentă poate asigura stabilitatea indiferent de cauza recidivei $(18,19,20)$. Deşi riscurile contenției permanente nu sunt încă bine cunoscute, utilizarea acesteia continuă să crească $(20,21)$.

\section{CONCLUZII}

Pentru a fi eficientă, contenţia trebuie să fie imediată, corect aplicată sau utilizată și pentru o perioadă lungă de timp. Cele mai utilizate dispozitive de contenție sunt: placa Hawley, gutierele termoformabile prin vacuum și retainerele colate. Niciuna 
dintre ele nu este perfectă. După cum am amintit, fiecare tip de aparat de contenție are avantaje și dezavantaje, iar medicul ortodont ar trebui să aleagă modalitatea prin care să prevină recidiva dentară

\section{BIBLIOGRAFIE}

1. Littlewood SJ, Milett DT, Doubleday B, Bearn DR, Worthington HV. Retention procedures for stabilishing tooth position after treatment with orthodontic braces. Cochrane Database of Systematic Reviews $2006 ; 1$.

2. Luther F, Nelson-Moon Z. Orthodontic retainers and removable appliances. Principles of design and use. UK, Wiley-Blackwell Publishing, 2013.

3. Edwards JG. A long term prospective evaluation of the circumferential supracrestal fibertomy in alleviating orthodontic relapse. AJODO. 1988;93:380-387.

4. Richardson ME, Gormley JS. Lower arch crowding in the third decade. European Journal of Orthodontics 1998;20:597-607.

5. McLaughlin RP, Bennett JC, Trevisi HJ. Systemized orthodontic treatment mechanics. Ed. Mosby International, 2001.

6. Rankema AM, Sips ETH, Bronkhorst E, Kujipers-Jagtman AM. A survey on orthodontic retention procedures in the Netherlands. Eur $\mathrm{J}$ Orthod. 2009;31:432-437.

7. Rowland $\mathrm{H}$, Hichens $\mathrm{L}$, Williams A et al. The effectiveness of Hawley and vacuum-formed retainers: A single-center randomized controlled trial. American Journal of Orthodontics and Dentofacial Orthopedics 2007;132(6):730-737.

8. Trickett E, Power S. A randomised clinical trial of thermoplastic retainer wear. Euro J Orthod. 2010;32:1-5.

9. Bearn DR. Bonded orthodontic retainers: A review. Am J Orth. Dentofac. 1995;108:207-213.

10. Lumsden KW, Saidler G, McColl JH. Breakage incidence with direct-bonded lingual retainers. Brit J Orthod. 1999;26:191-194.

11. Padmos JAD, Fudalej PS, Renkema AM. Epidemiological study of orthodontic retention procedures. Am J Orthod Dentofacial Orthop. 2018;153(4):496-504.

12. Andriekute A, Vasiliauskas A, Sidlauskas A. A survey study of protocols and trends in orthodontic retention. Prog Orthod. 2017;18(1):31. și să mențină poziția aliniată a incisivilor, a zâmbetului frumos, acesta fiind un aspect foarte important pentru oricare pacient care a solicitat și a fost tratat ortodontic.

Conflict of interest: none declared Financial support: none declared

13. Divya S, Urala AS. Orthodontic retention procedures: Orthodontistbased questionnaire study. Am J Orthod Dentofacial Orthop. 2018;154(5):617.

14. Kocher KE, Gebistorf MC, Pandis N, Fudalej PS, Katsaros C. Survival of maxillary and mandibular bonded retainers 10 to 15 years after orthodontic treatment: A retrospective observational study. Progr Orthod. 2019;20(1):28.

15. Decusară M, Şincar CD, Oana Chipirliu, Popa GV. Orthodontic treatment in adult patients with extraction of ectopic canines. Romanian Journal of Oral Rehabilitation 2019;11(4):59-64.

16. Decusară M, Șincar CD, Popa GV. Considerații privind particularitățile tratamentului ortodontic la adulți. Romanian Journal of Stomatology 2018;64(2):115-118.

17. Șincar DC, Leață R, Popa GV, Decusară M, Earar Kamel E. Clinical study of periodontal parameters during the orthodontic treatment. Romanian Journal of Oral Rehabilitation 2018;10(2):85-89.

18. Philippe J. About retention. Orthod Fr. 2010;81(3):221-226.

19. Kaya $Y$, Tunca M, Keskin S. Comparison of two retention aplliances with respect to clinical effectiveness. Turk J Orthod. 2019; 32(2):72-78

20. Knaup I, Wagner Y, Wego J, Fritz U, Jäger A, Wolf M. Potential impact of lingual retainers on oral health: comparison between conventional twistflex retainers and CAD/CAM fabricated nitinol retainers: A clinical in vitro and in vivo investigation. J Orofac Orthop. 2019;80(2):88-96.

21. Wouters C, Lamberts TA, Kuijpers-Jagtman AM, Renkema AM. Development of a clinical practice guideline for orthodontic retention. Orthod Craniofac Res. 2019;22(2):69-80. 